\title{
An Efficient and Guaranteed Cold-Chain Logistics for Temperature-Sensitive Foods: Applications of RFID and Sensor Networks
}

\author{
Ping-Ho Ting \\ Department of Hospitality Management and Department of Leisure Studies and Tourism Management, National Chi \\ Nan University, Taiwan. \\ phting@ncnu.edu.tw
}

\begin{abstract}
In this article, we propose a system with RFID and sensor networks to guarantee the keeping quality of low-temperature logistics. 3G network and GPS transportations are incorporated to this system to create a full-time monitoring system and all the processing will be transparent to the customers so that it could be a keeping-quality guarantee to the customers as well as a good strategy for differentiated marketing. This system can be connected with the customers' system so that all the processing, storage, and transportation temperatures can be sent to the customers through extranet and WEB server of suppliers. The customers' system can judge whether temperature data is normal or not before the foods receive. Owing to the fact that all the RFID tags and readers can be reused and not expensive at all, this system is very practical to be applied in the cold-chain logistics. A format of data exchange needs to be standardized in the future for broad applications.
\end{abstract}

Index terms - RFID, Sensor, Cold-chain Logistics, GPS, 3G, LTE.

\section{Introduction}

Cold-chain logistics management refers to a systematic logistics project which the temperature-sensitive products are always provided in low-temperature environment in every aspect such as production, storage, transportation, marketing and consumption, to ensure quality foods, and to reduce wear and tear of logistics. It is also a low-temperature logistics process which based on refrigeration technology. Cold chain constitutes four aspects of frozen processing, frozen storage, refrigerated transport and distribution, frozen sales. ${ }^{[9]}$ Typical temperature-sensitive products include dairy products, fresh food, horticultural products, blood, vaccines, and drugs, etc ${ }^{[2]}$. Some fresh foods such as Sashimi, pieces of raw fish require rigorous meat processing and transportation to guarantee the quality of the fish meat. This guarantee is especially important for the marketing to the high-end consumers. The processes from the process of fresh meat to the transportation to the consumer should be transparent to all the consumers. So far, the ocean recourses become rare and rare. The rarer the resources, the more important this cold chain logistics is. Cold chain is a supply chain system which ensures that the core requirements of maintaining low-temperature environment for the purpose of maintaining perishable foods quality, so it has higher requirements than the general logistics system at room temperature. In this article, we proposed the applications of RFID, sensor networks, and 3G or long term evolution (LTE) of Universal Mobile Telecommunications System (UMTS) networks to ensure the transparency described in the previous paragraph. The application of RFID can record the lot ID and sensed temperatures issued by sensors in packages during the storage, packaging and transportation. The RFID readers are installed in the fixed side of a transportation line. These readers are used to induce the tag reading on lot cases when sent to the transportation truck. The communication units in frozen truck are used to send the real-time temperature data issued by the temperature sensor of pack periodically to the data sever. The web server can publish all the data of foods ordered by the customer when the customer logs in the Extranets of suppliers. If the communication units can include the GPS receiver, the vehicles for the transportations can report its position piggybacked to these sensed temperature data. Some advantages of this additional device are that the high-value foods and vehicles can be traced once the rubbery occurring and the position of the foods can be transparent to the customers.

The remainder parts of this article are that we will make an introduction to the RFID technology first in section 2. Second, we will introduce our cold-chain system and its layered design in section 3. Third, marketing strategy, the benefits and cost of this cold chain system will be discussed in section 4. Finally, the conclusions will be reached in section 5 .

\section{RFID Technology}

RFID technology has recently become a viable replacement for the Universal Product Code (UPC) technology in many industries. Its fast growth and huge potential benefits have motivated a major move independently taken by Wal-Mart, the world's largest retailer, and the US Department of Defense (DoD), that 
requires their suppliers to install RFID tags by $2005^{[1][5]}$. In fact, RFID is a technology based on radio that uses radio frequency (RF) signal to make an automatic identification on static or moving objects and exchange digital information ${ }^{[1][3]}$. Generally speaking, a complete RFID system mainly consists of three parts, including tags, readers and antennas which are shown in Figure 1.

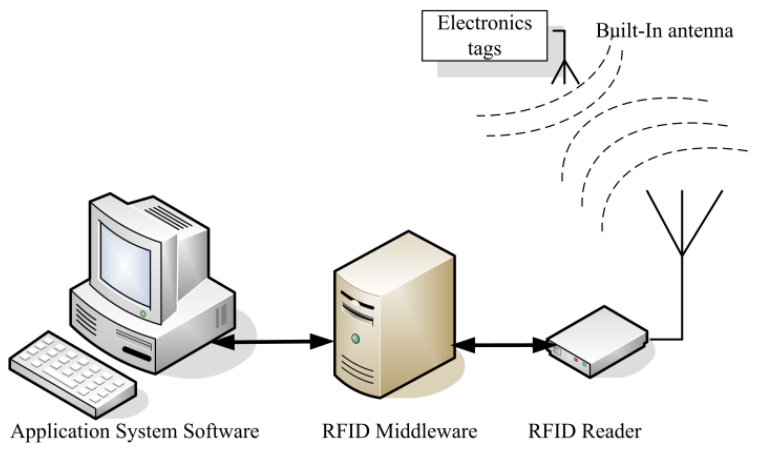

Figure 1. RFID system components

At its simplest form, a tag is a beacon announcing its presence to a reader. These types of tags are often seen in retail stores used to prevent theft by announcing their presence when taken past a reader. RFID tag capabilities, however, extend well beyond a simple beacon. Tag can hold a unique identity (UID) of 8 bytes in length and can be used for inventory management at global scale, such as a UPC. More than just an UID, a tag can carry re-writeable persistent storage and accessible via a reader. RFID tags are classified by its energy source as passive, semi-active (or semi-passive), and active. A passive tag has no battery of its own and makes use of the incoming radio waves broadcast by a reader to power its response. An active tag uses its own battery power to perform all operations. A semi-active tag uses its own battery power for some functions but, like the passive tag, uses the radio waves of the reader as an energy source for its own transmission. RFID readers employ tag-reading algorithms that are capable of identifying hundreds of tags per second. Once identified, a reader may read data from or write to a tag memory, depending on the permissions granted by the tag. RFID readers generally fall into two categories - high frequency (HF) and ultra-high frequency (UHF). Currently HF RFID systems adhere to the ISO standard while UHF RFID systems have yet to become standardized globally. Table 1 shows a comparison between HF and UHF RFID technologies. [8]
TABLE 1. COMPARISON OF HF AND UHF RFID TECHNOLOGY

\begin{tabular}{|c|c|c|}
\hline & HF RFID & UHF RFID \\
\hline \multirow[t]{3}{*}{ Frequency } & $13.56 \mathrm{MHz}$ & $902-928 \mathrm{MHz}$ N. America \\
\hline & & 860 - $868 \mathrm{MHz}$ Europe \\
\hline & & 950 - 956 MHz Japan \\
\hline $\begin{array}{l}\text { Read } \\
\text { Range }\end{array}$ & $10-20 \mathrm{~cm}$ & $3-6$ meters \\
\hline Read Rate & $50 \mathrm{tags} / \mathrm{sec}$ & 400 tags / sec \\
\hline $\begin{array}{l}\text { Memory } \\
\text { Size }\end{array}$ & $\begin{array}{l}64-256 \text { bits } \\
\mathrm{read} / \mathrm{write}\end{array}$ & $64-2048$ bits read/write \\
\hline $\begin{array}{l}\text { Power } \\
\text { Source }\end{array}$ & $\begin{array}{l}\text { Inductive } \\
\text { /Magnetic } \\
\text { Field }\end{array}$ & Capacitive / Electric Field \\
\hline Advantage & $\begin{array}{l}\text { Low Cost, } \\
\text { Standard } \\
\text { Frequency }\end{array}$ & High Speed, Longer read range \\
\hline
\end{tabular}

From the prospect of the tags with temperature sensors, the RFID tag is with large data storage which can be used to store the temperature data during the processing, transportation and receiving actions. The trick of this scheme is that the tag is low cost, easy to be operated and can be reused again and again. It can be read and written in the 30 meters range of RFID reader depending on the type of the tag. Whereas, a RFID tag can provide the ID code, and continuous records of temperature data with accurate time records, easier to define the responsibility and facilitate the retrospective information. Once the sensed temperatures received by the database server are abnormal since it violates the criterion defined in the standard operation procedure, which might initiate an event we set in the MIS system, the system should issue a warning message to the manager to get rid of this problem. This is what so called event management.

\section{System Architecture}

This guaranteed cold-chain logistic consists of 4 stages, refrigeration processing, refrigeration storage, refrigeration distribution, and refrigeration sale. In each stage, there are strict standard operation procedures to ensure the quality of the fresh foods from the processing center to the consumers. The system perspective in each stage is addressed in the following subsections.

\subsection{Refrigeration Processing and Storage Stage}

First of all, the RFID sensor on the package case will be initiated at the beginning moment of processing stage. Form this initiation, the sensor with RFID tag will record the timestamp and temperature on the memory of this RFID and will send this data to the RFID reader of the processing center. It is obvious that human-being cannot stand the very low-temperature environment such as 18 degrees below zero, so it is essential for the operator to process the raw material under very low temperature but greater than -18 degrees within a limited duration. For each batch operation, one EPC code is created and traced 
through the sensor with RFID EPC code. In the frozen processing center, the sensed data and timestamp will be sent out periodically to the RFID reader in this center, and the data will be relayed to the database server. In this scenario, the server will judge whether there are any abnormal conditions according to the temperature rule of processing center. The concept of this processing center and refrigeration storage is illustrated as in Figure 2.

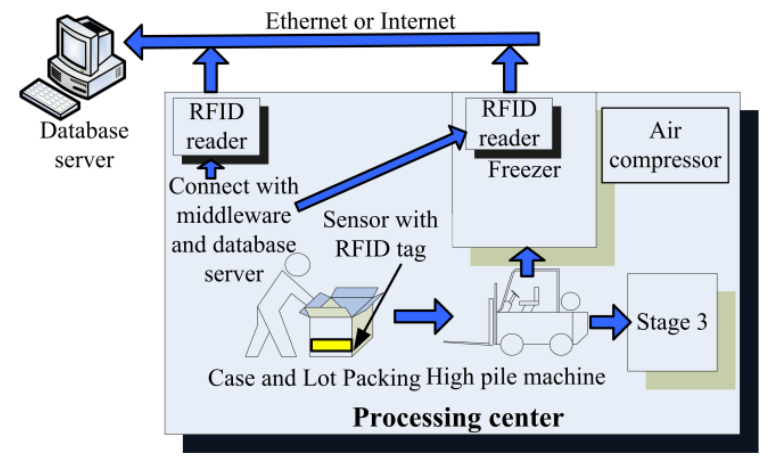

Figure 2. The concept of processing center and refrigeration storage

It is noted that cold-chain products ranging different products on the storage conditions have different requirements, not the same with non-demanding cold-chain foods, when warehousing, according to information obtained by the RFID reader, distribute the foods to the right storage area exactly. Once the processing or storage processes have been started, the sensor with RFID tag will send the EPC, temperature, and timestamp to the database server periodically. It is essential to report this temperature conditions from the processing procedure to guarantee the quality of foods with temperature sensitivity. The web server connected with the database server can publish all the data if the customer logs in the extranet system by inputting user name and password through an extranet port number instead of the normal port 80 to ensure the security of this extranet.

\subsection{Transportation and Sale Stage}

Once the cold-chain foods have been sent out from the processing center or frozen storage, these foods will be sent to the truck through a transportation line or high pill machines. The transportation line might be a mechanical transportation line or a walk to the truck, but there will be a RFID reader attached on this line. Whenever the lot packs sent out through the line in the range of induction, the RFID reader will beep and send the EPC of this lot pack and the vehicle number of this truck to the database server to hint their relationship. Once the customer logs in the web server and make a query about the conditions of their ordered foods, all the details including the frozen conditions and foods trace indicated by the GPS of the truck will be shown in detail. The database server of the customer can receive this data stream to monitor the quality of the ordered foods at any time or in any place. Hence, once the cold-chain foods are received, the maintain quality of these foods has been determined by the database server of the customer. The server can place strict rules on this data stream, and if there are any violations to these rules, the customer can reject the foods receiving before the arrival of these foods. At the same time, the database server of the supplier will make an event notice to the manager, and the RFID reader on the truck can also issue a warning message to the driver if the air compression on this truck is out of order. This innovation can provide the customer for the guaranteed quality of temperature-sensitivity foods. At the same time, it is also a best marketing strategy to make a differentiation from other cold-chain logistics. The concept of this system diagram is illustrated in Figure 3.

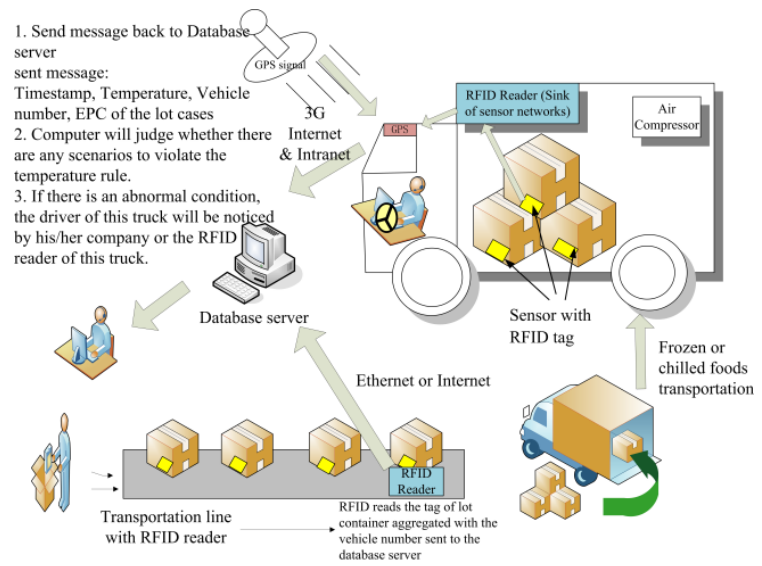

Figure 3. The concept of system diagram for transportations of cold-chain logistics

In fact, when an RFID tag is given sensing capabilities, the line between RFID and sensor network becomes blurred. Many active and semi-active tags have incorporated sensors into their design, allowing them to take sensor readings and transmit them to a reader at a later time. They are not quite sensor network nodes because they lack the capacity to communicate with one another through a cooperatively formed ad-hoc network, but they are beyond simple RFID storage tags. In this way, RFID is converging with sensor networking technology ${ }^{[6]}{ }^{[10]}$. Mateusz ${ }^{[7]}$ describes CargoNet, a system of low-cost, micro power active sensor tags that seeks to bridge the current gap between wireless sensor networks and radiofrequency identification (RFID). From the other direction some sensor nodes are now using RFID readers as part of their sensing capabilities. The SkyeRead Mini M1 made by SkyeTek is an example of an RFID reader designed to mate directly with the Crossbow Mica2Dot sensor motes ${ }^{[4]}$. It is noted that the sensor networks in the processing center, freezer, and frozen storage in truck are very simple to be one-hop. The data transfer can be achieved by sensor networks or the initiation of RFID reader because the distance between tag and reader is very short, i.e. below 3 meters. If there are 30 lot containers in the truck, and only one lot container's temperature is abnormal to be received, we can judge it that the sense function of this sensor is out of order. This abnormal sensor should be verified in 
the loading procedure to the truck if the sensed data is abnormal at that time. As to the data transmission, the future fourth-generation $(4 \mathrm{G})$ wireless technologies, such as LTE and WiMAX offer high bandwidth for data transfer. The uplink data rate of the future $4 \mathrm{G}$ may be up to several Mega bits per second (Mbps). If there are total 100 records of sensed data per minute to be sent through $3 \mathrm{G}$ or future $4 \mathrm{G}$ in the truck, the required throughput of these data stream is about $960 \mathrm{bps}$ if we assume the sizes of EPC, coded temperature, GPS positions, and other essential data are $64,8,16$ and 8 bits, respectively. Hence, even the low data rate of the current $3 \mathrm{G}$ network can afford this traffic transmission certainly. The telecommunication company, Chunghwa Telecom in Taiwan claims that now they can offer the data rate up to $10 \mathrm{Mbps}$ for the $3.5 \mathrm{G}$, high speed downlink packet access (HSDPA). In this network, the data sent from the truck can be denser, i.e. sending the sensed data per 10 seconds and the estimated data rate is only $1600 \mathrm{bps}$. Hence, the transmission time is short to 0.0016 seconds if we assume the data rate is up to $100 \mathrm{Mbps}$. If there are total 100 trucks for transportation, the required throughput can be $160 \mathrm{Kbps}$ only. The computation loading for this data processing is certainly very light for the database server.

\section{Discussion}

The guaranteed low-temperature system can be discussed in the following subsections.

\subsection{Marketing Strategy}

As stated in the previous section, this guaranteed low-temperature logistics can be a best strategy for differentiated marketing. The definition of differentiated marketing is a sales growth strategy in which several market niches or population segments are targeted with different products for each niche or segment. Here, this guaranteed low-temperature logistic can be treated as a different product for the niches of transparency and quality guarantee to the customers. Although this strategy is not costly to imitate, it cannot be a sustained competency. However, the first mover in this innovation strategy can gain the trust and good brand image for the customers from the prospective of customer relationship management (CRM). This differentiated marketing is expected to create value in the short term at least.

\subsection{Cost and Economic Benefits}

The main primary applied obstacle to use RFID is cost problem compared with the bar code system. Despite the possible condition to produce the RFID chip massively, the cost of RFID cannot be lower than that of bar code system because the cost of the bar code system is near to zero. Hence, the deployment of RFID on the merchandise of the supermarket is evaluated to be impossible generally. From the viewpoints of environmental protection, commercial RFID may be an impact to our environment. Fortunately, all the RFID chips used in this guaranteed cold-chain logistics are reusable, so the cost of RFID tag and reader is not a concern here. Additionally, the cost of $3 \mathrm{G}$ or $3.5 \mathrm{G}$ communication will be lower and lower as the cloud computing is developing because of the increase of market demands. This tremendous increase in need for the technique of cloud computing will drive the cost down of the communication infrastructure due to the factor of economic of scale. In Taiwan, the cost of using $3 \mathrm{G}$ networks for one telephone number is about twelve American dollars per month today. This cost is very reasonable and cheap. In summary, the cost of this guaranteed system is very low and should be practical in all cold-chain logistics. As to the economical benefits to implement this system, it is really very valuable by applying the known $4 \mathrm{P}$ marketing strategy. For example, the top customers in Sashimi make strict requirement for the processing and transportation activities. Any system which can guarantee the cold-chain logistics will let these customers pay higher cost to taste the Sashimi transported by this system. Hence, the economic benefits of this system are too valuable to evaluate.

\subsection{RFID and Traceability}

Recently, food safety is highly concern by many counties, RFID has the feature of traceability to ensure and promote food safety in some complex supply chain, especially in temperature-sensitive foods. For people, they will keep more confidence in health and secure. For industries, it promotes internal operating efficiency and further enhances the competitiveness of enterprises.

\section{Conclusion}

In this article, a guaranteed low-temperature logistic is proposed. This system has many benefits to apply it and it incurs low cost overhead. For the differentiated marketing consideration, it is a very good strategy to apply this guaranteed cold-chain logistics. The LTE-A, the future of $3 \mathrm{G}$ and GPS technologies combined with the concept of Intranet and Extranet make it transparent to all the customers so that the customers can trust the products certainly. A detailed standard for this system needs to be devised in more detail so that the vendors, suppliers and customers can follow it and be collaborative based on this system.

\section{Reference}

[1] A. B. Maurizio, L. Francesca, M. Francesca, "Instant collision resolution for tag identification in RFID networks", Ad Hoc Networks, Vol. 5, No. 8, pp. 1220-1232, 2007.

[2] Bo Yan, Danyu Lee, "Application of RFID in Cold Chain Temperature Monitoring System, “, ISECS International Colloquium on Computing, Communication, Control, and Management 2009, pp: 258-261.

[3] Chen Jian, "RFID based Management Information System Design and Implementation", Electronics University of Science and Technology, 2006 
Software engineering.

[4] Crossbow Inc., "Mica2Dot Series," http://www.businesswire.com/news/home/2004051 8005605/en/Crossbow-Technology-leader-Smart-D ust-Smallest-Mote, downloaded 10 Sept. 2013.

[5] DOD, DOD RFID website, https://acc.dau.mil/CommunityBrowser.aspx?id=5 8647, downloaded 10 Sept.2013.

[6] Loc Ho, Melody Moh, Zachary Walker, Takeo Hamada, Ching-Fong Su, "A Prototype on RFID and Sensor Networks for Elder Healthcare: Progress Report", in: Proceedings of the 2005 ACM SIGCOMM workshop on Experimental approaches to wireless network design and analysis.

[7] Mateusz Malinowski, Matthew Moskwa, Mark Feldmeier, Mathew Laibowitz, Joseph A. Paradiso, "CargoNet: A Low-Cost MicroPower Sensor Node Exploiting Quasi-Passive Wakeup for Adaptive Asychronous Monitoring of Exceptional Events", SenSys'07, November 6-9, 2007, Sydney, Australia.

[8] WINMEC (Wireless Internet for Mobile Enterprise Consortium), Home page, downloaded 20 Feb 2005. http://www.winmec.ucla.edu/index.asp.

[9] Zhang Ruifu, "Analysis of cold-chain logistics system architecture in hotel and catering industry", Commercial Research, 2007.

[10] Zhen Zhen, Wang Fei, Xia Xiang, "RFID-based real-time wireless temperature monitoring system design and implementation", Engineering Technology, 2007.

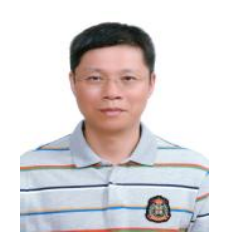

Ping-Ho Ting is an associate professor at the Department of Hospitality Management and the Department o of Leisure Studies and Tourism Management, National Chi Nan University, Nantou, Taiwan (email:phting@ncnu.edu.tw). He received a $\mathrm{PhD}$ in Business Administration from National Central University. Dr Ting's major research interests include hotel information system, data mining, intelligent system, e-commerce and website evaluation. Now he has many papers published in a variety of journals including Cornell Hospitality Quarterly, Journal of travel \& tourism marketing, Asia Pacific Journal of Travel Research, International Journal of Technology Management, International Journal of Information Technology \& Decision Making, Journal of Internet Technology, Cyberpsychology, Behavior, and Social Networking, Journal of Research and Practice in Information Technology, Journal of Universal Computer Science etc. 